\title{
Father-targeted nutrition education improves early initiation and breastfeeding exclusivity: The case of Kisumu county, Kenya
}

\author{
Lynette Aoko Dinga*, Beatrice Nyanchama Kiage-Mokua, Florence Kyallo \\ Department of Human Nutrition Sciences, Faculty of Agriculture, Jomo Kenyatta University of Agriculture and \\ Technology, Nairobi, Kenya
}

\begin{abstract}
Objectives: Mothers who have physical and emotional support during the early post-partum period have a greater likelihood of succeeding in breastfeeding. This study examined the effect of nutrition education on fathers in improving early initiation of breastfeeding and exclusive breastfeeding in the first 3 months of the infant's life.

Methods: An interventional study was conducted in Kisumu East Sub County, Kenya. All the women who were 6 months pregnant between January and April 2016 and attending the antenatal clinic at Kisumu County hospital were included in the study. Once contacted, each woman provided the telephone contact of the father-to-be. The later were then invited to a meeting at the hospital within 2 weeks of first contact to get their consent to participate in the study. The pair were asked to pick one among pre-numbered papers which randomly put them in either the intervention or control group with each group having 145 pairs. A total of 290 fathermother pairs were recruited. The study site was selected based on the high infant mortality rate in the region. No intervention was given in the control group while both father-mother pairs in the intervention group received nutrition education on breastfeeding. The study participants were followed up until the children birthed reach 3 months of age.

Results: At $97.1 \%$, initiation of breastfeeding within an hour of birth was significantly higher among the intervention group compared to $52.1 \%$ in the control group $(p<0.001)$. Likewise, at $81.1 \%$, sustained exclusive breastfeeding at 3 months was significantly higher among the intervention group compared to $63.4 \%$ in the control group $(p=0.001)$.

Conclusion: The intervention positively impacted on early initiation and sustenance of exclusive breasting in the first 3 months of life. Nutrition education at the health facility or community level should involve fathers as key influencers of the breastfeeding process, which contributes to improved infant feeding practices.
\end{abstract}

Keywords: Father, Support, Nutrition Education, Early initiation, Breastfeeding, Kisumu, Kenya.

Accepted on November 15, 2018

\section{Introduction}

Support from the infant's father in the form of active participation in the decision to breastfeed, having a positive attitude and knowledge about the importance of breastfeeding, has been shown to have a strong influence on the initiation and duration of breastfeeding [1,2]. The World Health Organization (WHO) and United Nations Children's Emergency Fund (UNICEF) recommend initiation of breastfeeding within the first hour after birth otherwise known as early initiation of breastfeeding [3]. This, combined with exclusive breastfeeding, reduce child morbidity and mortality in the first two years of life [3], and can reduce $22 \%$ of neonatal deaths [4]. Sub-Saharan Africa remains the region with the highest infant mortality rate with 56 deaths per 1,000 live births compared to the global rate of 32 deaths per 1,000 live births [3]. In Kenya, infant mortality rate is 36 deaths per 1,000 live births [5]. Globally, under half of the newborns are breastfed within an hour of delivery, with only $44 \%$ in the African region [6]. In Kenya, $62 \%$ of infants are breastfed within an hour after birth [7], which is below the recommended WHO target coverage of 90\% [8]. Fathers can make a difference by influencing positive infant feeding practices but they need information in order to make this difference $[9,10]$. Engagement of fathers through educating them on breastfeeding can greatly improve infant feeding and health behaviors [11]. This study assessed the impact of nutrition education targeting fathers on improving breastfeeding practices.

\section{Literature Review}

For over 25 years, various strategies have been put forward and implemented to support early, exclusive, and continued breastfeeding. In the $1980 \mathrm{~s}$, breastfeeding was promoted as part of the "child survival revolution" along with growth monitoring, oral rehydration, and immunization. The largest part of the breastfeeding promotion efforts focused on health provider skills, hospital practices, and policies [12]. In 1990, 
representatives from 30 countries and multilateral and bilateral partners gathered to make a global action plan to reverse declining breastfeeding rates [13]. From this meeting emerged the Innocenti Declaration on the Protection, Promotion, and Support of Breastfeeding. Maternity services were linked to the community through Step 10: "foster the establishment of breastfeeding support groups and refer mothers to them on discharge from the hospital or clinic," but this step proved to be an obstacle for many programmes [13].

The community was endorsed by the World Health Assembly in 2002 as a key component of the comprehensive Global Strategy for Infant and Young Child Feeding [14]. The strategy reaffirms the operational targets of the Innocenti Declaration and adds five additional targets, including one that particularly refers to the community: make certain that the health and other relevant sectors protect, promote, and support exclusive breastfeeding for six months and continued breastfeeding up to two years of age or beyond, while providing women access to the support they need in the family, community, and workplace. The Global Strategy states that community-based support networks should be welcomed within the health care system and should "participate actively in the planning and provision of services". Many women have limited contact with health care providers, but they do have daily contact with family members, friends, neighbors, employers, and others in their community who can influence their infant feeding behavior [13].

From a familial and socio cultural context, infant and young child feeding is rooted within traditional relationships in which both relatives and breadwinners have influence and even authority over options and modes of infant feeding [15]. Interventions that involve men as agents of positive change are fairly few in number, although the male engagement approach is timely, as research has indicated that men themselves, as well as their partners, would prefer that they play a more active role during pregnancy, delivery, and infant care, but that societal and health system norms seldom support this. There has been acknowledgment that to improve maternal, infant, and young child nutrition, health structures need to focus on and support fathers, because fathers play a significant role in providing helpful and emotional support to mothers and children. Engaging fathers is also essential because of the significance of both the father-infant relationship and the couple relationship to overall individual and family well-being [16].

\section{Methodology}

\section{Study design}

The study used an interventional design, with randomization of study participants into two groups, an intervention and a control group.

\section{Study setting}

The study was conducted in Kisumu County Hospital located in Kisumu East Sub-county, Kenya. The sub-county covers an area of $1,960.2 \mathrm{Km}^{2}$ and has a 2016 projected population of 544,166 with $3.24 \%(14,715)$ being pregnant women and $25.9 \%(117,629)$ women of reproductive age [17]. The main occupation of men living in Kisumu East Sub County is casual labor in light industries located in the city center while women are mainly housewives. Infant mortality rate is high for Kisumu County at 95/1000 [17]. Kisumu East Sub County which was randomly selected while Kisumu County hospital was selected because it is the main government hospital within the Sub County.

\section{Sample}

Sample size was calculated using the formula by Johnson et al. [18]. The study considered an effect size of $20 \%$ with reference to better results outcome from that of a study done in Turkey of $15 \%$ and standard deviation of 0.58 [2]. Considering a $10 \%$ attrition rate, the sample size was 145 per study group making a total of 290 .

\section{Recruitment and inclusion criteria for study participants}

All the women who were 6 months pregnant between January and April 2016 and attending the antenatal clinic at Kisumu County hospital were eligible for inclusion in the study. A total of 290 father-mother pairs were recruited during that period. Once recruited, each woman provided the telephone contact of the father-to-be, who was subsequently invited to participate in the study. A meeting between the father-mother pairs and the study team took place within 2 weeks of the first contact. By picking one among pre-numbered papers, the pair were randomly allocated into either the intervention or control group. Those in the intervention group would then receive nutrition education session.

Inclusion was of: women who were 6 months (23-27 weeks) pregnant and attending the antenatal clinic at Kisumu County hospital at the time of recruitment; women who were living together with the father of the unborn child; women who were from Kisumu east sub-county; women who were planning to breastfeed; fathers to the child expected by the pregnant women and who were willing to be visited at home. Women who were 6 months pregnant and attending the antenatal clinic at Kisumu County hospital but were not from Kisumu East Sub County were excluded as were women who indicated that they did not plan to breastfeed and those with documented chronic diseases or are very ill.

The respondents were informed of the objectives of the study and the interviewer sought their written consent to participate in the study. All information and conversations provided to the investigators by the participant were regarded as confidential.

\section{Data collection}

The researchers developed nutrition education materials on recommended breastfeeding practices with specific information tailored for fathers emphasizing their unique and vital role in the success of breastfeeding. The educational material was based on the UNICEF integrated infant and young child feeding counseling training course of 2012 [19] and Infant and Young Child Feeding and Gender manual prepared by UNICEF's Infant and Young Child Nutrition (IYCN) Project for the men's groups activities [20]. The father-mother pair in the intervention group received a 3-hour nutrition education session after recruitment at the health facility with similar content on exclusive breastfeeding and male involvement. This 
was different from the routine health education provided health facilities which usually targets women during antenatal visits.

A total of 145 father-mother pairs were trained with each session having 15 pairs. The training content included maternal nutrition, early initiation of breastfeeding, benefits of exclusive breastfeeding, positioning and attachment, human milk expression, breastfeeding in the context of HIV and male involvement. On male involvement, fathers were enlightened on the supportive role they can play, ensuring there is adequate nutritious food for the mother during pregnancy and lactation, supporting the mother during delivery by encouraging the mother to put the baby to the breast within an hour of birth, rubbing the mothers back to stimulate milk production, holding the baby for the mother to get rest, cup feeding the baby on expressed mother's milk, helping in taking care of older children and doing household chores. Lecture, group discussions and role play was used to cover the sessions. The sessions were delivered by 3 trained nutritionists in a classroom setting. At the end of the sessions, a summary of the main points on exclusive breastfeeding was provided to the participants in form of a leaflet.

Quantitative data was collected at baseline during recruitment, 3 months after recruitment and 6 months after recruitment using semi structured questionnaires to assess breastfeeding initiation, early post-partum breastfeeding, and postpartum breastfeeding support received from the father, and sustained exclusive breastfeeding at 3 months post-partum. WHO guideline on the assessment of IYCF indicators [21] was used as the reference on how to assess breastfeeding practice. Father's support was based on father's practices during the mother's delivery and post-partum periods. Different paternal actions during these periods were assessed with each positive response regarded as a supportive action suggesting that the father participated in that particular activity.

\section{Data analysis}

Quantitative data was cleaned in the field then later coded and entered into SPSS version 21 and cleaned before analysis. Descriptive analysis was done to assess early postpartum breastfeeding. Associations between early initiation, breastfeeding exclusivity and breastfeeding support from the father was assessed using chi-square tests.

Factor analysis was performed to summarize paternal practices into 7 major themes grouped as in Table 1. Each type of father's support was scored dichotomously either 0 or 1 . Since types of father's support consisted of more than 1 item, a score of 0 was given when either item received a negative response, whilst a score of 1 was given only when all items received positive responses.

\section{Results}

\section{Early initiation of breastfeeding}

Figure 1 shows early initiation of breastfeeding among the study participants. Majority $(74.3 \%)$ of the mothers initiated breastfeeding within an hour after birth with a significantly higher proportion among the intervention group $(97.1 \%)$ compared to the control group $(52.1 \%) x^{2}=74.18, \mathrm{p}<0.001$. Mothers in the intervention group were 31 times more likely to initiate breastfeeding within an hour of birth compared to the mothers in the control group $(\mathrm{OR}=30.8 ; 95 \% \mathrm{CI}$ : $10.8-87.8$; $\mathrm{p}<0.001)$.

\section{Provision of pre-lacteal feeds}

The introduction of pre-lacteal feeds is shown in Table 2. Overall, 26.1\% of children were given pre-lacteal within the first 3 days after delivery. Mothers in the intervention group were significantly less likely $(7.2 \%)$ to introduce pre-lacteal feeds in the first three days of life compared to those in the control group $(44.4 \%), x^{2}=50.0, \mathrm{p}<0.001$. Plain water was a common pre-lacteal given $(43.8 \%)$ followed by sugar-salt-water solution $(35.6 \%)$.

\section{Feeding on colostrum}

Most $(97.9 \% \mathrm{n}=274)$ infants in both the intervention and control group were fed on colostrum in the first 3 days after birth. Mothers in the intervention group were significantly more likely $(100 \%)$ to feed the baby on colostrum in the first 3 days after birth compared to those in the control group $(95.8 \%), x^{2}=5.9$, $\mathrm{p}=0.02$ (Figure 2).

\section{Father's support}

Mothers were asked if the newborn's father helped with breastfeeding during the first 72 hours after the birth of the child. At $87.6 \%$, mothers who reported receiving support from the father were significantly higher among the intervention group compared to $37.2 \%$ in the control group $x^{2}=90.9, p$ $<0.001$. Majority (74.5\%) of those who initiated breastfeeding within an hour had received support from the father. At $74.5 \%$, mothers who reported receiving support from the father were significantly higher among the intervention group compared to $36.1 \%$ in the control group $x^{2}=34.5, p<0.001$. The kind of support given by the fathers at birth as reported by the mothers is indicated in Table 3.

Table 1. Paternal practices.

\begin{tabular}{|l|l|}
\hline Household chores and responsibilities & Father helps with cleaning, cooking, home maintenance, shopping, laundry and bill pay. \\
\hline Caring for the baby & Father helps care for baby such as diapers, playing, putting to sleep, soothing, and bathing. \\
\hline Feeding the baby & $\begin{array}{l}\text { Father is involved with breastfeeding process, helps to swaddle baby after feeding, helps to burp baby after feeding, helps with } \\
\text { positioning and latching. }\end{array}$ \\
\hline Caring for the mother & $\begin{array}{l}\text { Father allows mother time to sleep, rest, do other things, pump, break from the baby, massages, buys or prepares healthy foods } \\
\text { to support or increase milk production }\end{array}$ \\
\hline Encouragement and motivation & $\begin{array}{l}\text { Father offers words of encouragement and motivation such as "you can do it", "keep going", "I'm proud of you" and practical } \\
\text { support with breastfeeding challenges }\end{array}$ \\
\hline Being in agreement & Father feels breastfeeding is a joint responsibility, agrees on breastfeeding method and decision \\
\hline Favourable environment & $\begin{array}{l}\text { Father helps create a relaxed and/or stress free environment for mother to breastfeed, keeps things positive and/or has a } \\
\text { positive attitude about breastfeeding }\end{array}$ \\
\hline
\end{tabular}


Citation: Dinga LA, Kiage-Mokuac BN, Kyallo F. Father-targeted nutrition education improves early initiation and breastfeeding exclusivity: The case of Kisumu county, Kenya. J Food Sci Nutr. 2018;1(3):12-7.

\section{Initiation of breastfeeding after birth}

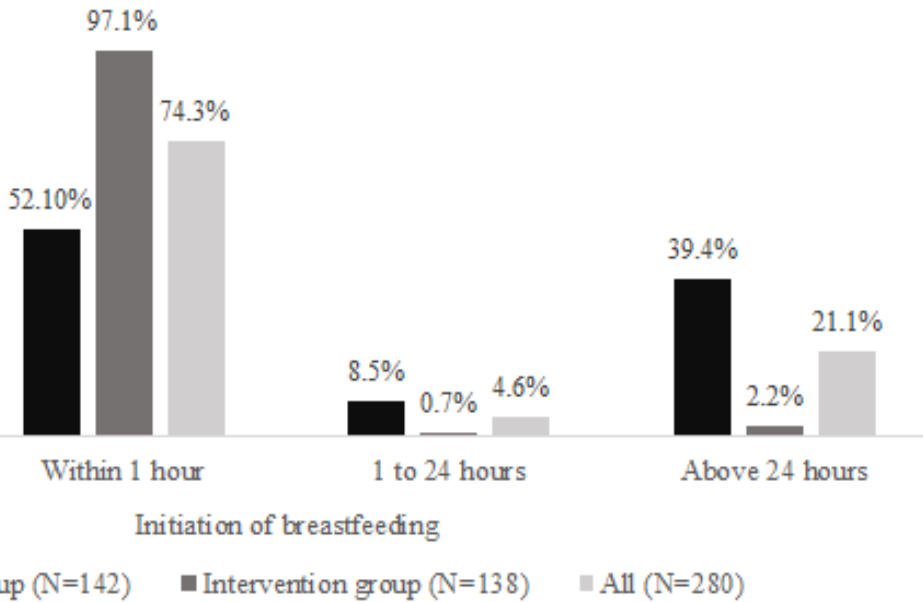

Figure 1. Early initiation of breastfeeding.

Given colostrum

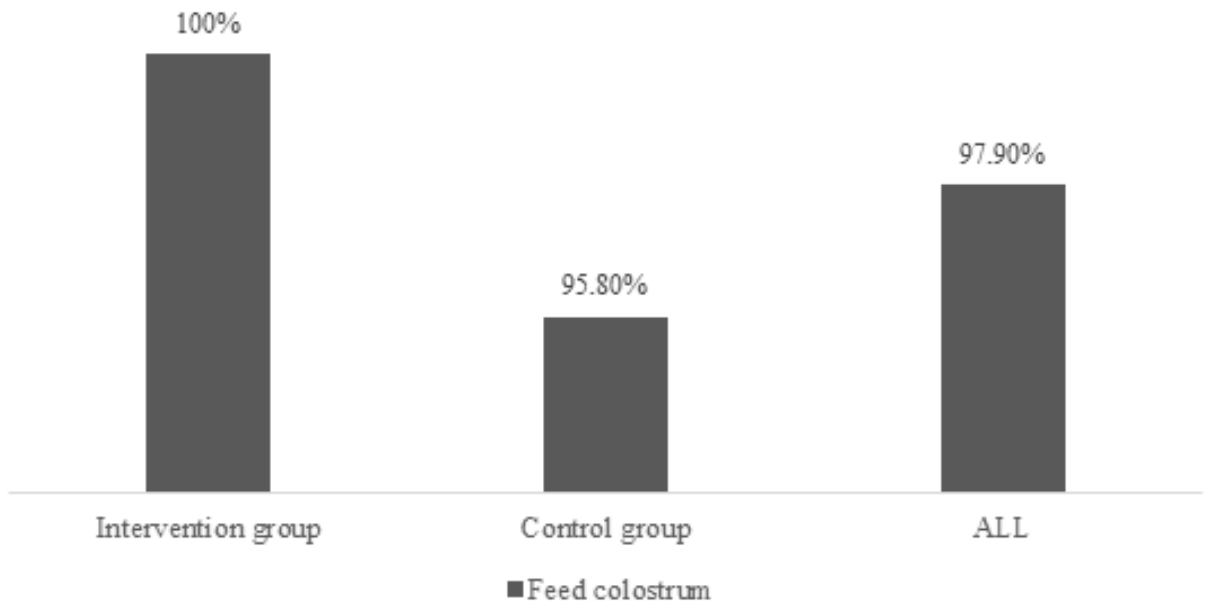

Figure 2. Feeding the neonate on colostrum.

Table 2. Post-partum feeding of infants among study participants in Kisumu County.

\begin{tabular}{|c|c|c|c|}
\hline PRE-LACTEAL GIVEN & $\begin{array}{c}\text { INTERVENTION } \\
\text { GROUP N (\%) }\end{array}$ & $\begin{array}{c}\text { CONTROL GROUP } \\
\mathbf{N}(\mathbf{\%})\end{array}$ & $\begin{array}{c}\text { ALL N } \\
\mathbf{( \% )}\end{array}$ \\
\hline PLAIN WATER & $5(50)$ & $27(42.9)$ & $32(43.8)$ \\
\hline SUGAR-SALT-WATER & $4(40)$ & $22(34.9)$ & $26(35.6)$ \\
\hline OTHER MILK & $1(10)$ & $10(7.0)$ & $11(15.1)$ \\
\hline TEA/INFUSIONS & $0(0)$ & $3(4.8)$ & $3(4.1)$ \\
\hline INFANT FORMULA & $0(0)$ & $1(0.7)$ & $1(1.4)$ \\
\hline
\end{tabular}

Table 3. Comparison of father support at birth among the intervention and control groups.

\begin{tabular}{|c|c|c|c|c|}
\hline \multirow{2}{*}{ Support given } & \multirow{2}{*}{$\begin{array}{l}\text { Control group } \\
(\mathrm{N}=142) n(\%)\end{array}$} & \multirow{2}{*}{$\begin{array}{l}\text { Intervention group } \\
(\mathrm{N}=138) \mathrm{n}(\%)\end{array}$} & \multicolumn{2}{|c|}{ Chi-square } \\
\hline & & & $\mathbf{x 2}$ & $\mathbf{p}$ \\
\hline Household responsibilities & $66.7(92)$ & $73.9(105)$ & 1.77 & 0.18 \\
\hline Caring for the baby & $60.1(83)$ & $71.8(102)$ & 4.26 & $0.04^{*}$ \\
\hline Feeding the baby & $59.4(82)$ & $72.5(103)$ & 5.37 & $0.02^{*}$ \\
\hline Caring for the mother & $58.7(81)$ & $73.2(104)$ & 6.6 & 0.1 \\
\hline $\begin{array}{l}\text { Encouragement and } \\
\text { motivation }\end{array}$ & $44.2(61)$ & $72.5(103)$ & 23.15 & $0.00^{*}$ \\
\hline
\end{tabular}

Table 4. Comparison of father support at 3 months among the intervention and control groups.

\begin{tabular}{|c|c|c|c|c|}
\hline \multirow{2}{*}{ Support given } & \multirow{2}{*}{$\begin{array}{l}\text { Control group } \\
(\mathrm{N}=142) \mathrm{n}(\%)\end{array}$} & \multirow{2}{*}{$\begin{array}{c}\text { Intervention } \\
\text { group }(\mathrm{N}=138) \\
\mathrm{n}(\%)\end{array}$} & \multicolumn{2}{|c|}{ Chi-square } \\
\hline & & & $x 2$ & $\mathbf{p}$ \\
\hline Household responsibilities & $55.1(79)$ & $67.4(93)$ & 2.59 & 0.11 \\
\hline Caring for the baby & $54.3(77)$ & $69.9(96)$ & 6.99 & $0.01^{*}$ \\
\hline Feeding the baby & $48.8(70)$ & $70.1(97)$ & 12.86 & $0.00^{*}$ \\
\hline Caring for the mother & $47.1(67)$ & $69.1(95)$ & 13.63 & $0.00^{*}$ \\
\hline Encouragement/motivation & $45.7(65)$ & $72.1(100)$ & 19.71 & $0.00^{*}$ \\
\hline Being in agreement & $50.7(72)$ & $64.7(89)$ & 5.49 & $0.02^{*}$ \\
\hline Favourable environment & $48.6(69)$ & $64.0(88)$ & 6.62 & $0.01^{*}$ \\
\hline
\end{tabular}

\section{Exclusive breastfeeding at 3 months}

Exclusive breast feeding (feeding an infant with no food or drink other than breast milk) was computed based on 24-hour recall. Overall, $71.5 \%$ of the study participants sustained exclusive breastfeeding at 3 months. At $81.1 \%$, sustained exclusive breastfeeding at 3 months was significantly higher among the intervention group compared to $63.4 \%$ in the control group 
$x^{2}=10.6, \mathrm{p}=0.001$. At 3 months, mothers in the intervention group were 2.5 times more likely $(\mathrm{OR}=2.5$; 95\% CI: $1.4-$ $4.4 ; \mathrm{p}=0.001)$ to practice exclusive breastfeeding compared to the mothers in the control group. At 3 months post-partum, mothers reported receiving support from the father, which was significantly higher among the intervention group (84.8\%) compared to $39.0 \%$ in the control group $x^{2}=60.3, p<0.001$. The kind of support given by the fathers at 3 months as reported by the mothers is indicated in Table 4.

\section{Discussion}

This study finding indicate that the father plays an important role in breastfeeding outcomes at the early stages, with more mothers in the intervention group practicing early initiation compared to the mothers in the control group. The findings are similar to that of a previous study done in Italy which tested the effectiveness of a 2-hour class delivered to fathers on breastfeeding promotion, where breastfeeding was initiated by $74 \%$ of women whose partners attended the intervention class as compared with $41 \%$ of women whose partners did not receive the intervention [22]. A similar study in the United States also reported an increase in early initiation rate from 71 to $76 \%$ to $83 \%$ in three months following dissemination of breastfeeding information to the fathers [23].

In this study, more mothers in the intervention group reported receiving support from the father towards breastfeeding compared to the mothers in the control group. Consistent with previous studies, father's supportive actions remove stressors so that the mother is enabled to breastfeed successfully [24,25]. A study in Australia showed that mothers whose husbands received breastfeeding education before the birth, liked breastfeeding the most and were supported the most by their husbands [9].

This study found that physical and emotional support by fathers is important for breast-feeding success. Mothers in the intervention group were able to identify more positive support that they had received from the father compared to the mothers in the control group, possibly as a result of the fathers' having participated in the nutrition education sessions and gaining knowledge on breastfeeding and what role they can play. Similar study in Brazil has also reported that fathers may provide support to breast-feeding mothers by relating information learned in the intervention to breast-feeding mothers [24]. Father's support to the mother and child can be in multiple ways such as affirming the woman's decision to breast-feed and showing physical support to the mother and child in between or during feedings [26].

\section{Conclusion}

Father involvement and support of breastfeeding has a role in early initiation and sustenance of exclusive breastfeeding for the first 3 months post-partum. Nutrition education targeting the father helps them to play a more supportive role which positively impacts on breastfeeding practice. This study suggests that health education programs need to be developed that target fathers especially as a means of not only increasing breastfeeding knowledge among fathers but also potentially increasing early initiation and sustenance of exclusive breastfeeding among mothers.

\section{Funding Statement}

All authors acknowledge funding from German Academic Exchange Service (DAAD).

\section{Conflict of Interest Statement}

All the authors do not have any possible conflicts of interest.

\section{References}

1. UNICEF, State of the world's children, Maternal and New Born Health. UNFPA, New York, 2009.

2. Edmond KM, Zandoh C, Quigley MA, et al. Delayed breastfeeding initiation increases risk of neonatal mortality. Pediatri. 2006;117:380-6.

3. UNICEF/WHO/World Bank/UN-DESA Population Division, 2017. Levels and trends in child mortality report, estimates developed by the UN inter-agency group for child mortality estimation. New York, USA: UNICEF. 2017:30-5.

4. UNICEF/WHO. Global breastfeeding scorecard in 2017: tracking progress for breastfeeding policies and programmes. New York: UNICEF/WHO. 2017.

5. Kenya National Bureau of statistics (KNBS) and ICF Macro. Kenya Demographic and Health Survey 20102014. Kenya, Calverton, Maryland: KNBS and ICF Macro. 2014;139-200.

6. UNICEF. Improving Child Nutrition: The achievable imperative for global progress. UNICEF, New York. 2013.

7. Sloand E, Astone NM, Gebrian B. The impact of fathers' clubs on child health in rural Haiti. Am J Public Health. 2010;100(2):201-4.

8. Republic of Kenya (RoK). Kisumu County strategic plan 2013-2018. Nairobi, Kenya, Ministry of state for planning, National Development and Vision 2030. 2012;15-35.

9. Johnson RA, Dean W, Wichern Selvin S. Practical Biostatistical Methods. Belmont: Duxbury Press. 1995.

10. Pisacane A, Continisio GI, Aldinucci M, D'Amora S, et al. A controlled trial of the father's role in breastfeeding promotion. J Pediatr. 2005;116:e494-98.

11. UNICEF. The community infant and young child feeding counselling package. New York: UNICEF. 2012.

12. Jelliffe DB, Jelliffe EF. Programmes to Promote Breastfeeding. New York: Oxford Medical Publications. 1988.

13. WHO/UNICEF/USAID. Indicators for assessing infant and young child feeding practices. Geneva, World Health Organization. 2008.

14. WHO. The optimal duration of exclusive breastfeeding. Report of an Expert Consultation. Geneva: World Health Organization. 2003:8-14.

15. Greene ME, Mehta M, Pulerwitz J, et al. Involving Men in Reproductive Health: Contributions to Development. Paper prepared for the UN Millennium Project to contribute to the report Public Choices, Private Decisions: Sexual and 
Reproductive Health and the Millennium Development Goals. 2006.

16. Goodman J. Becoming an involved father of an infant. Journal of Obstetric, Gynecologic, and Neonatal Nursing. 2005;34(2):190-200.

17. Martin S, Mukuria A, Maero P. Engaging men to increase support for optimal infant feeding in Western Kenya. USAID, Kenya. 2009.

18. WHO. Indicators for assessing infant and young child feeding practices. Part II: Measurement. World Health Organization, Geneva. 2009.

19. Wolfberg AJ, Michels KB, Shields W, et al. Dads as breastfeeding advocates: results from a randomized controlled trial of an educational intervention. Am J Obstet Gynecol 2004;9(3):708-12.

20. Stremler J, Lovera D. Insight from a breastfeeding peer support pilot program for husbands and fathers of Texas WIC participants. J. Hum. Lact. 2004;20(4):417-22.
21. Tohotoa J, Maycock B, Hauck YL, et al. Dads make a difference: an exploratory study of paternal support for breastfeeding in Perth, Western Australia. Int. Breastfeed. 2009;4:15.

22. Susin LR, Giugliani ER, 2008. Inclusion of fathers in an intervention to promote breastfeeding: impact on breastfeeding rates. J Hum Lact 24(4):386-392.

23. Schmidt M, Sigman-Grant M. Perspectives of low-income fathers' support of breastfeeding: an exploratory study. J. Nutr Educ. 2000;32:31-7.

24. Arora S, McJunkin C, Wehrer J, et al. Major factors influencing breastfeeding rates: mother's perception of father's attitude and milk supply. Pediatr. 2000;106:e67.

25. Kenosi M, Hawkes CP, Dempsey EM, et al. Are fathers under used advocates for breastfeeding? Irish Med J. 2011;104:313-5.

26. Rempel LA, Rempel JK. The breastfeeding team: the role of involved fathers in the breastfeeding family. J Hum Lact. 2011;27(2):115-21.

\section{*Correspondence to:}

Lynette Aoko Dinga

Department of Human Nutrition

Sciences

Faculty of Agriculture

Jomo Kenyatta University of

Agriculture and Technology

Nairobi

Kenya

Tel: 254725681922

E-mail: linetaoko@yahoo.com 